\title{
Experimental investigation of stress-strain conditions in punching zone of flat slabs
}

\author{
Valery Filatov ${ }^{1, *}$ \\ ${ }^{1}$ Samara State Technical University, Institute of Architecture and Civil Engineering, \\ 194, Molodogvardeyskaya St., 443001, Samara, Russia
}

\begin{abstract}
The technique and results of experimental study on the test specimens of the stress-strain condition of flat reinforced concrete slabs of a girderless framework at punching by columns of square and rectangular section are presented. The punching shear strength of slabs at rectangular columns can be lower than at square columns with a similar length of the control perimeter. The research of influence of a form of a column crosssection on the stress-strain condition of a reinforced concrete slab in a punching zone is conducted. The comparative analysis of distribution of concrete and reinforcement deformations of reinforced concrete slabs on column perimeter depending on a ratio of the sides of cross section is made. The results of the research of cracking in a zone of punching of reinforced concrete slabs are presented here. Results of the conducted research allow expanding the base of experimental data of the considered subject and promoting improvement of modern positions in the theory of power resistance of reinforced concrete. New experimental data received in the research corresponded with the earlier offered hypothesis that in a slab there is a zone of the constrained deformation located along the perimeter around the rectangular column.
\end{abstract}

\section{Introduction}

Columns of rectangular section with the height several times surpassing its width have wide distribution at construction of buildings with monolithic girderless floors [1-3]. The application of rectangular columns (pylons) allows increasing lateral stiffness of the building. The stress-strain condition in a punching zone of flat reinforced concrete slab supported on pylons (in comparison with a square or round columns) is characterized by considerable non-uniformity distribution of strains along the control perimeter around the column. This peculiarity was observed experimentally by several researches such as Moe [4], Hawkins et al. [5], Muttoni, Sagaseta et al. [6, 7] and any others. In experiences of the researchers mentioned above there was a concentration of concrete strains of the slab in zones of the columns corners. At tests of samples with round section columns that concentration of concrete strains wasn't observed.

This deformation peculiarity of flat reinforced concrete slabs, as test results show, can reduce their bearing capacity at punching by rectangular columns (pylons) [8-10]. The

*Corresponding author: vb_filatov@mail.ru 
punching shear strength of RC flat slabs at rectangular columns can be overestimated if the non-uniform distribution of strains along the control perimeter around the column is neglected in the calculations. In design codes various approaches are applied to account for this feature. In USA code ACI 318-11 a correction factor is applied which depends on the side ratio of column. In Model Code MC2010 and Swiss design code SIA 262 it is recommended to reduce the size of control perimeter. There are also other suggestions for improvement of calculated techniques [11-15].

The research of power resistance of reinforced concrete constructions in the combined stress (the joint action of normal and cross forces, bending moments) has an empirical basis, owing to concrete work as a composite elastic-plastic material with violation of discontinuity (cracks formation) [16-19]. The structural behavior is examined in the experimental path to check put-forward theoretical prerequisites and suggest subsequent development of computational models and calculation procedures [20-24].

As the calculation of punching shear forces in slabs has an empirical basis, the actual task is the expansion of test data base which allows to improve calculation procedures by taking into account various factors (constructive, force et al) influencing the slabs power resistance to punching.

\section{Materials and Methods}

The test specimens represented a fragment of a reinforced concrete monolithic unit of a column pair of the round or rectangular section and a flat slab. The varied parameter was the aspect ratio of a column section. The four specimens have been tested:

- CMR-D - a column of round section with a diameter of $210 \mathrm{~mm}$.

- CMR-1 - a column of square section with a side size of $200 \mathrm{~mm}$.

- CMR-2.5 - a column of rectangular section of the size $200 \times 500 \mathrm{~mm}$.

- CMR-4 - a column of rectangular section of the size $200 \times 800 \mathrm{~mm}$.

The slab thickness of all specimens made $140 \mathrm{~mm}$. Reinforcement at the tensioned side of a slab was carried out by reinforcing grids made of hot-rolled reinforcement bars Class A500 with a $14 \mathrm{~mm}$ diameter and $100 \mathrm{~mm}$ step. The reinforcement ratio was the same for all the specimens $(1.41 \%)$. The measured values of effective depth in the specimens ranged from $107 \mathrm{~mm}$ to $110 \mathrm{~mm}$ as shown in Table 1. Crushed dolomites' limestone was used for the concrete with a maximum aggregate size of $20 \mathrm{~mm}$. The measured concrete cube strength $f_{c u}$ at time of testing ranged from $29 \mathrm{MPa}$ to $40 \mathrm{MPa}$ as shown in Table 1 . The detailed description of the construction, the geometrical sizes of specimens and their reinforcing are presented in [10].

Table 1. Summary of test specimens and experimental results.

\begin{tabular}{|c|c|c|c|}
\hline Test & $\mathrm{d}_{\text {avg }}, \mathrm{mm}$ & $f_{c u}, \mathrm{MPa}$ & $\mathrm{V}_{\text {test }}, \mathrm{kN}$ \\
\hline CMR-D & 110 & 40.0 & 284.9 \\
\hline CMR-1 & 108 & 34.7 & 272.0 \\
\hline CMR-2.5 & 107 & 29.0 & 281.3 \\
\hline CMR-4 & 109 & 35.1 & 328.4 \\
\hline
\end{tabular}

Loading of test specimens was carried out in test frame placed underneath the reaction floor. The loading force was created by a hydraulic jack and applied to the lower side of a column. The loading of specimen was made gradually by $5 \%$ of a theoretical failure load. The hold time of the specimen under loading at each step was 15 minutes. At each step of loading the indications of strain and dial gages, schemes of crack formation and development were registered. The test frame construction and the technique of specimen loading are presented in [10]. The specimen CMR-D in the process of testing is shown in 


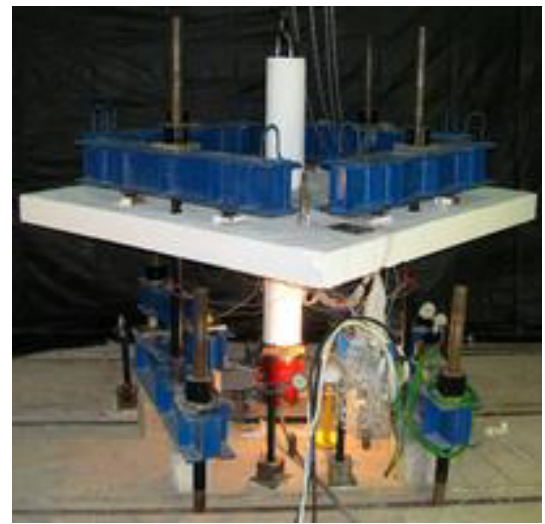

Fig. 1. Testing of the specimen CMR-D.

The strains of concrete of the slab compressed side and the tensioned reinforcement bars was measured by means of strain gages placed in radial and tangential directions (fig. 2).

a)

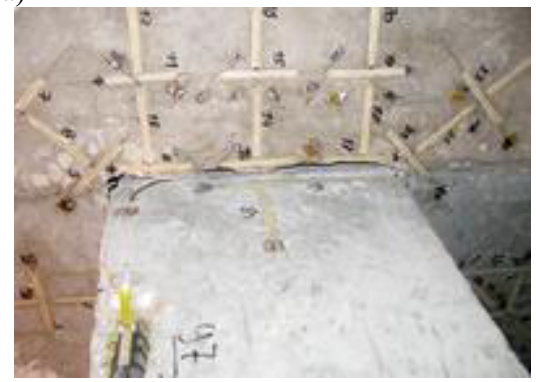

b)

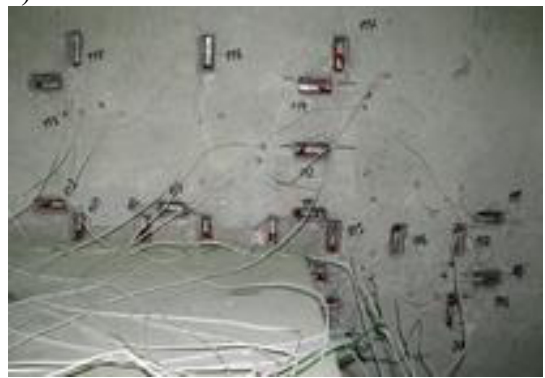

Fig. 2. Position of strain gages on concrete (a) and reinforcement (b).

Deflections of slab were measured by means of dial gauges as the difference in slab displacements at a given point and near the surface of the column. Width of cracks opening on a slab surface was measured by means of microscope.

\section{Results}

The destruction of all specimens was fragile, due to punching slabs by the column. The values of failure loads are specified in Table 1.

The crack formation in slabs of all specimens had similar image. The first radial cracks with opening width $0.05 \mathrm{~mm}$ were formed at the level of loading $0.25-0.3$ from the ultimate load $\left(\mathrm{P}_{\mathrm{ult}}\right)$ on the top surface of the slab from the sides of the column and developed to the external contour of the slab. Formation of tangential cracks was noted at the level of loading (0.45-0.5) $\mathrm{P}_{\text {ult }}$. When the crack formation began the cracks openings was insignificant, the formation of new cracks was more essential. At the level loading $0.85 \mathrm{P}_{\text {ult }}$ the intensity of crack formation considerably decreased, the process of their opening was prevailing. On the limit stage before destructing the width of radial cracks reached $0.3 \mathrm{~mm}$, and of tangential cracks (at column sides) $0.7-0.8 \mathrm{~mm}$. The greatest intensity of crack formation in the slab was observed on the sites near columns corners.

Based on the results of measuring the strains of concrete and reinforcement of slabs, graphs of the distribution of concrete tangential strains on compressed surface of the slab along the sides of the column are carried out (fig. 3) and the graphs of distribution of strains 
of the reinforcing bars located along the sides of the column at distance of $50 \mathrm{~mm}$ from her faces (fig. 4). The graphs were carried out for a quarter of column section at the loading close to a failure load.

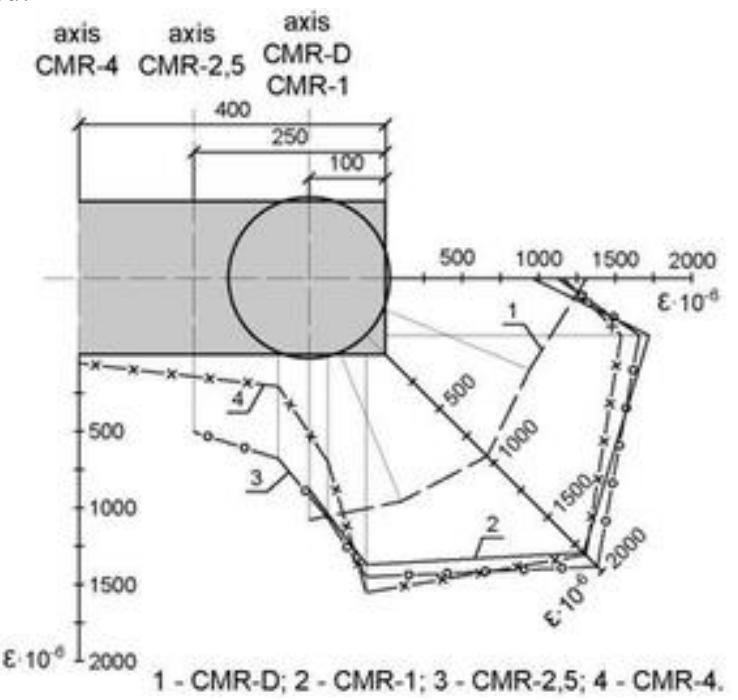

Fig. 3. Distribution of tangential strains of concrete on the compressed surface of slab.

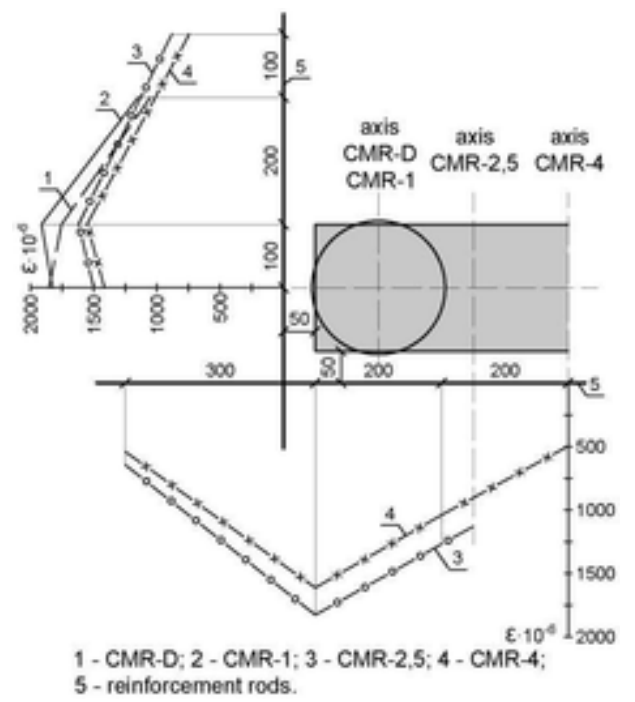

Fig. 4. Strain distributions of reinforcement bars located along the column side.

Distributions of radial strains of concrete on the compressed surface of slab and strain distributions of reinforcement bars, perpendicular to the sides of the column have shown a smaller variability at changing the form and sides ratio of the column section, therefore they are not considered in this article.

\section{Discussion}

The analysis of distribution of tangential strains of concrete on the compressed surface of slab (fig. 3) for specimen with round section of column (CMR-D) shows that strains along 
the perimeter of the column change slightly - the scatter values don't exceed $20 \%$. For specimen with square section of column (CMR-1) the maximum values of tangential strains of the slab concrete are observed near the column corners. In the direction from column corner to its mid-section a considerable strains decrease is observed (from $24 \%$ to $45 \%$ ). For specimens with rectangular section of columns (CMR-2.5 and CMR-4) maximum values of concrete strains of the slab are also observed near column corners. The distribution of tangential concrete strains of the slab along the short side of the column has the same character, as well as for CMR-1 specimen. Along the long side of the column section it is observed that tangential concrete strains of the slab in the direction from the column corner to its mid-section decrease and they reach the minimum there. In comparison with the slab concrete strains at the corner of the column, tangential strains in the middle of the long side of the column section make $26 \%$ and $3 \%$ for the specimens of CMR-2.5 and CMR-4 respectively.

The peculiarities of tangential strains distribution of concrete on the compressed slab side noted in the experimental study confirm the previously proposed hypothesis about constrained deformation zone that located in the slab along the perimeter around the rectangular column and having the form of an ellipse [14]. The constrained deformation zone is evidenced by the nature of crack on the compressed side of slab at punching by a rectangular column. On the slab compressed side of the CMR-1 specimen no cracks were observed, and in the CMR-4 specimen, at punching, on the compressed side of slab, the characteristic cracks were formed along the long sides of the column section (fig. 5). The trajectory of cracks had an elliptic configuration with the maximum removal from the column face in the middle of the section long side.

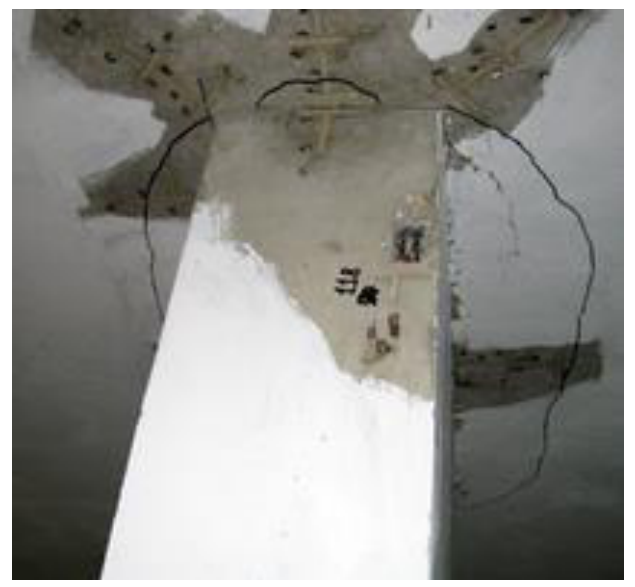

Fig. 5. Cracks on the compressed slab side CMR-4 specimen.

The analysis of strains distribution in the reinforcement bars of the slab located along the face of the column section (fig. 4) shows that the maximum value of strains is observed in the section, coinciding with the column side (a peak value). The exception makes a specimen CMR-D for which the maximum value of strains is noted on an axis of symmetry of the specimen. For specimen CMR-1 the strains of slab reinforcement bars on an axis of symmetry of the specimen are slightly (3\%) less than the peak value. At the distance of 200 $\mathrm{mm}$ from the column face the strains of reinforcement bar make $60 \%$ of the peak value for CMR-D and CMR-1 specimens.

For CMR-2.5 and CMR-4 specimens strains distribution in the reinforcement bar of the slab along the short side of the column is similar to the CMR-1 specimen. The strains of reinforcement bar on the axis of symmetry of specimen is $7.4 \%$ and $8.8 \%$ less than the peak 
value for the specimens CMR-2.5 and CMR-4 respectively. At the distance of $300 \mathrm{~mm}$ from the column face the strains of reinforcement bar make $54 \%$ and $48 \%$ of the peak value for the specimens of CMR-2.5 and CMR-4 respectively. It should be noted that the peak values of the strains of reinforcement bar along the short side of the column for the specimens of CMR-2.5 and CMR-4 15-19\% are lower than for the CMR-1 specimen.

The strains distribution at reinforcement bar of the slab along the long side of the column for the specimens of CMR-2.5 and CMR-4 are characterized by a considerable fall in strains to the middle of the column section compared with the peak value. The value of strains of reinforcement bar of the slab on the axis of symmetry of the specimen makes $60 \%$ and $31 \%$ of the peak value for specimens of CMR-2.5 and CMR-4 respectively. At the distance of $300 \mathrm{~mm}$ from the column face the strains of reinforcement bar make $35 \%$ and $34 \%$ of the peak value for specimens of CMR-2.5 and CMR-4 respectively.

The analysis results of the slab reinforcement strains along the column sides of the rectangular section show that the strains of reinforcement bar of the slab decrease from the column corner to its mid-section. The decrease value of reinforcement strains of the slab depends on the ratio of the column section sides. Thus, in the constrained deformation zone along the perimeter around rectangular column, not only tangential strains of the compressed slab concrete, but also strains of the tensioned reinforcement bars located parallel to the column face decrease.

\section{Conclusions}

In the research presented here new experimental data about the stress-strain condition of flat reinforced concrete slabs in a punching zone are obtained. The analysis is made about the influence of the form and ratio of the column section sides on the value and nature of distribution of the compressed concrete strains and those of tensioned reinforcement bars in the punching zone. The results analysis of the research presented here allow drawing the following conclusions.

1. Strength reduction of flat reinforced concrete slabs at punching by columns of a rectangular section happens owing to a less intense part of control perimeter of the slab located in the middle of the long side of the column section. With the increase in the aspect ratio of the column section the length of a less intense part of the control perimeter increases as well as the strength reduction.

2. In the research the tangential strains of the compressed slab concrete were considered though shear stresses are a cause of destruction at punching. Comparing the distributions of tangential strains of the compressed concrete of slabs received in the very research with the distributions of shear fields of slabs received by calculation in [6] it is possible to see a considerable similarity of their configuration. It allows to draw a conclusion about the prevailing influence of concrete tangential deformations on the value of shear stresses and, respectively, on the punching strength.

3. The peculiarities of distribution of concrete tangential strains of the slab compressed side and those of reinforcement bars along the column sides mentioned in the experimental study confirm the earlier offered hypothesis that in a slab there is a zone of the constrained deformation located along the perimeter around rectangular column and it has an ellipse form. The concrete and reinforcement bars strains in the zone of the constrained deformation decrease that leads to the insufficient use of strength characteristics of materials and decrease in the punching shear strength. For CMR-2.5 and CMR-4 specimens the decrease in concrete tangential strains of the slab compressed side makes $74 \%$ and $97 \%$, the decrease in strains of reinforcement bars along the long side of the column section makes $40 \%$ and $69 \%$ respectively. 


\section{References}

1. V.P. Popov, D.V. Popov, A.Yu. Davidenko, MATEC Web of Conferences 86, 01014 (2016)

2. A.O. Mateyko, Urban Construction and Architeture 3(24), 74-78 (2016) DOI: 10.17673/Vestnik.2016.03.12

3. V.P. Generalov, E.M. Generalova, Urban Construction and Architeture 2(10), 12-16 (2013) DOI: 10.17673/Vestnik.2013.02.2

4. J. Moe, Dev. dep. bul. D47, PCA (1961)

5. N.M. Hawkins, H.B. Falssen, R.C. Hinojosa, ACI Spec. Publ. SP-30, 127-146 (1971)

6. J. Sagaseta, L. Tassinari, M. Fernandez Ruiz, A. Muttoni, Eng. Struct., 77, 17-33 (2014)

7. J. Sagaseta, A. Muttoni, M. Fernandez Ruiz, L. Tassinari, Mag. Conc. Res., 63(6), 441-457 (2011)

8. T. Susanto, H.K. Cheong, K.L. Kuang, J.Z. Geng, ACI Struct. J., 101(5), 678-687 (2004)

9. V.B. Filatov, E.P. Bubnov, MATEC Web of Conferences 86, 01007 (2016)

10. V.B. Filatov, E.P. Bubnov, Industrial and civil engineering 2, 86-91 (2017)

11. A. Muttoni, ACI Struct. J., 105(4), 440-450 (2008)

12. C.E. Broms, ACI Struct. J., 87(3), 292-304 (1990)

13. N.I. Karpenko, B.S. Sokolov, O.V. Radaykin, Industrial and civil engineering 1, 28-30 (2013)

14. V.B. Filatov, Bulletin of civil engineers 5(40), 80-84 (2013)

15. V.B. Filatov, Proceedings of the Samara scientific center of the Russian Academy of Sciences, 16, no. 4-3, 646-649 (2014)

16. E.N. Kodysh, N.N. Trekin, D.N. Trekin, Concrete and reinforced concrete-glance at future : III All-Russian (II International) Conference on concrete and reinforced concrete, I, 69-75 (2014)

17. V.I. Travush, V.I. Kolchunov, N.V. Klyueva, Industrial and civil engineering 3, 4-11 (2015)

18. V.I. Travush, S.G. Emel'yanov, V.I. Kolchunov, Industrial and civil engineering 7, 20 $27(2015)$

19. A.G. Tamrazyan, Industrial and civil engineering 7, 26-27 (2012)

20. N.N. Trekin, D.A. Pekin, Industrial and civil engineering 7, 17-20 (2014)

21. A.N. Bolgov, A.Z. Sokurov, Concrete and reinforced concrete - glance at future: III All-Russian (II International) Conference on concrete and reinforced concrete, IV, 139-149 (2014)

22. A.N. Bolgov, D.M. Yakimovich, Concrete and reinforced concrete-glance at future : III All-Russian (II International) Conference on concrete and reinforced concrete, I, 224-233 (2014)

23. V.B. Filatov, A.A. Suvorov, Procedia Engineering 153, 144-150 (2016)

24. A.G. Tamrazyan, Yu.N. Zvonov, Industrial and civil engineering 7, 24-28 (2016) 